\title{
An alternative to clapping for the NHS: online support for NHS placement students
}

\author{
Anna Judd-Yelland \\ University of Bedfordshire
}

Keywords: remote drop-in; healthcare students; undergraduate transition into HE; specialist academic skills support; Covid- 19 .

\section{The challenge}

I will report on the experiences of the first-year undergraduate healthcare student intake of 2020/21 and how we adapted the face-to-face (f2f) drop-in service for students from two schools using a specialist Academic Skills Team approach. These students were provided with pre-recorded lectures to watch, webinars to attend and lots of guided learning to 'just get on with'. As a learning developer (LD), supporting assignment writing skills, I will reflect on what we learnt from the process, and how we overcame barriers to learning. Ali (2020) argues that the key ingredients for success in switching to online integrated learning are resources, staff readiness, confidence, student accessibility and motivation.

It is well documented that within a university context, anonymity is a barrier to establishing new learner identity, and students need to develop peer and lecturer relationships to feel a sense of belonging (Scanlon, et al., 2007; Eberlie and Hobrecht, 2021). Previous cohorts, despite also having moved to emergency online learning, had pre-established friendships, social networks and relationships with lecturers. Our intake of 2020/21 knew no one, lacked day-to-day interaction with other students and staff, and had little opportunity to develop their networks, identify new academic expectations and develop a sense of belonging. 


\section{The response}

Czerkawski and Lyman's (2016) design framework for fostering online engagement emphasises the need for synchronous interaction, collaboration and opportunities for feedback when designing online learning experiences. Walker and Koraleski's (2020) study found that although there was a reduction in affective engagement, there was an increase in cognitive engagement, and overall learners engaged better with synchronous remote content than with asynchronous content during the rapid online transition. Specifically, they found that learners preferred participation in breakout rooms with lecturers, engaging with active learning via polls (73\%) and chat (64\%). Abou-Khalil et al. (2021) also found that $49 \%$ of the student responses in their study identified synchronous Q\&A as the most engaging learner-instructor strategy. They also reported that the most effective learner-learner engagement strategy was group chat to discuss course-related issues. Breakout rooms facilitated learners' asking and answering questions of each other and the lecturer in real time to clarify assessment requirements, discuss reading lists and tackle drug calculation practice questions.

Using a synchronous learner-to-learner and learner-to-instructor interaction approach, we adapted our pre-Covid-19 multidisciplinary f2f drop-in service to be remote. The f2f drop-in had been a well-used student-centred service with high levels of student engagement. Workload planning was also a factor; drop-ins required minimal teaching preparation time from an already busy team. We offered weekly remote drop-in sessions to the intake of 2020/21 healthcare students. We scheduled sessions to fit around nursing, our biggest cohort with over 200 students. Remote drop-in sessions mirrored the f2f drop-in in their ability to be responsive to students' needs. Collaborate was used as the virtual classroom of choice in my institution and is a tool student were already familiar with.

We used breakout rooms to deliver a multi-discipline academic skills approach involving librarians, numeracy tutors, computer skills trainers and assignment support tutors. Students could move between breakout rooms and have a multitude of queries addressed, listen to other students' questions and support each other in a small group environment, maximising learner-learner engagement. Although attendance was voluntary, regular attendees were able to develop relationships maximising learner-learner and learner- 
instructor engagement. Students dialled into sessions via phones whilst on NHS placements, an unexpected outcome that challenged my thinking regarding how students on placement integrate the academic demands of their course.

There were higher levels of engagement within sessions compared to structured webinars for the same cohorts. We witnessed the development of engagement and belonging between students and a core group of regular attendees in all four breakout rooms. In effect, they had informally created a community of practice (Wenger, 1998). Students' feedback reported developing knowledge, confidence and identity, most prominent in maths, where attendees reported developing skills in drug and fluids calculations. One student reported that without the additional support she would have dropped out. Mature learners who were home-schooling their children reported that they were able to pop into sessions according to home demands. More efficient use of teaching time was also observed as the drop-in reported 95 hours staff time $=239$ student queries answered.

The risk for us was opening the sessions to all healthcare students simultaneously and managing students' expectations without knowing which courses and how many students would attend. The drop-in was much better received by some courses than others. Weekly attendance fluctuated anywhere between zero and 40 students. Tracking student attendance by number and type of query and course was something we did not get right straight away. As LDs, we were too focused on which specialist service students used, and only when requested by a midwifery lecturer did we realise we could not account for attendance by course. This was easily addressed, and we started to track by course too. We identified that the initiative was unable to directly address any barriers students experienced to digital inclusion.

Reflecting on the data, we could say that students on courses with higher UCAS tariffs were less engaged with online drop-in sessions. Although this could account for the variation in attendance according to course witnessed in the remote drop-in, without more detailed research and analysis of the student demographic and student experience, it is not possible to conclude that UCAS tariff alone contributed to higher numbers of students attending from nursing over other healthcare courses. 


\section{Recommendations}

I would recommend running remote drop-in services for placement students on a multicampus $\mathrm{HEl}$ to provide academic skills support and maintain academic links with students on clinical placements. This could be targeted to support specific assessments before submission and offered to students at all levels. Enlisting the support of an additional LD to greet students, filter students into breakout rooms by enquiry type, and track student attendance would ensure a smoother student experience and enable richer insights into the impact on student retention and engagement - something I felt we were not able to achieve and would also recommend.

This case study has aimed to illustrate to what extent providing a remote academic skills drop-in was able to enhance student engagement and academic skills support to NHS undergraduate students transitioning into HE. A key factor in its success was the established collaborative relationships within the specialist LD team involved, our detailed knowledge of the course requirements, and the prior six months experience of learning about remote delivery. This experience put us in a position in which we were prepared to take risks. Without these factors, the transition to remote drop-in would not have been possible or enjoyable for staff or students.

\section{References}

Abou-Khalil, V., Helou, S., Khalifé, E., Chen, M.A., Majumdar, R. and Ogata, H. (2021) 'Emergency online learning in low-resource settings: effective student engagement strategies', Education Sciences, 11(1): 24. Available at: https://doi.org/10.3390/educsci11010024 (Accessed 18 August 2021).

Ali, W. (2020) 'Online and remote learning in higher education institutes: a necessity in light of COVID-19 pandemic', Higher Education Studies, 10(3), pp.16-25. Available: https://doi.org/10.5539/hes.v10n3p16 (Accessed: 18 August 2021).

Czerkawski, B.C. and Lyman, E.W. (2016) 'An instructional design framework for fostering student engagement in online learning environments', TechTrends, 60, p.532-539. 
Available at: https://doi.org/10.1007/s11528-016-0110-z (Accessed: 18 August 2021).

Eberlie, J. and Hobrecht, J. (2021) 'The lonely struggle with autonomy: A case study of first-year university students' experiences during emergency online teaching' Computers in Human Behaviour. 121 https://doi.org/10.1016/j.chb.2021.106804

Scanlon, L., Rowling, L. and Weber, Z. (2007) “'You don't have like an identity ... you are just lost in a crowd": forming a student identity in the first-year transition to university', Journal of Youth Studies, 10(2), pp.223 -241. Available at: https://doi.org/10.1080/13676260600983684 (Accessed: 18 August 2021).

Walker, K. and Koraleski, K. (2020) 'Student and instructor perceptions of engagement after the rapid online transition of teaching due to COVID-19', Natural Sciences Education, 50(1), pp.1-10. Available at: https://dx.doi.org/10.1002\%2Fnse2.20038 (Accessed: 18 August 2021).

Wenger, E. (1998) Communities of practice: learning, meaning and identity. Cambridge: Cambridge University Press.

\section{Author details}

Anna Judd-Yelland has been a learning developer at the University of Bedfordshire for the past seven years. She is a Fellow of the Higher Education Academy and has also been awarded ALDinHE Certified Practitioner status. She works predominantly with the Schools of Nursing and Healthcare Practice to develop students' academic literacy skills. 